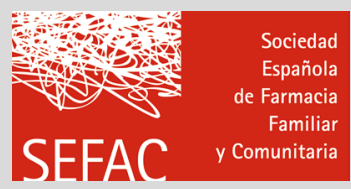

\title{
Mirar atrás para seguir adelante
}

\author{
Nicanor Floro Andrés Rodríguez \\ Director de FARMACÉUTICOS COMUNITARIOS
}

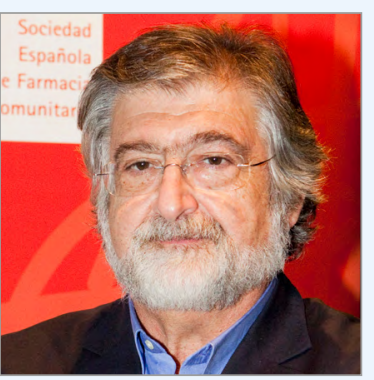

Nicanor Floro Andrés

\section{PALABRAS CLAVE}

Revista electrónica, investigación, estadísticas y datos numéricos, indexación, farmacia comunitaria

\section{KEYWORDS}

e-journal, research, statistics and numerical data, indexing, community pharmacy
Hace unos días hemos recibido la noticia de que nuestra revista, FARMACÉUTICOS COMUNITARIOS, había sido evaluada por la MIAR (Matriz de Información para el Análisis de Revistas de la Universidad de Barcelona), que le había asignado en el año 2017 un índice ICDS (Índice Compuesto de Difusión Secundaria) de 9,6 (en 2016 había sido de 6,8), con lo que se había situado por encima de muchas revistas indexadas en Scopus, FECYT o Redalyc. El ICDS es un indicador que muestra la visibilidad de la revista en diferentes bases de datos científicas de alcance internacional y en repertorios de evaluación de publicaciones periódicas. Un ICDS elevado significa que la revista está presente en diferentes fuentes de información de relevancia internacional.

Como se puede ver en la web (http:// www.farmaceuticoscomunitarios.org/es/ indexacion) de la revista, FARMACÉUTICOS COMUNITARIOS está indexada ya en numerosas bases de datos y confiamos en aumentar en los próximos meses el número de indexaciones.

La Sociedad Española de Farmacia Familiar y Comunitaria (SEFAC) publicaba desde 2006 la revista el e-farmacéutico, dirigida por nuestro recordado primer presidente Paco Martínez. También desde 2005, la Sociedad Farmacéutica del País Valenciano, posteriormente integrada en SEFAC como delegación regional, publicaba su propia revista con la cabecera Farmacéuticos Comunitarios.

En 2009 SEFAC decidió reorientar la filosofía de su revista, enfocándola más a la investigación científica en farmacia comunitaria, carente hasta entonces de un espacio específico y que, por lo tanto, se enfrentaba a grandes dificultades para la difusión de los interesantes logros que se iban obteniendo de la investigación en esta modalidad de ejercicio. Se definían como objetivos: "promover, fomentar y consolidar la investigación en farmacia comunitaria en España y acercar a los socios temas profesionales de interés". Se pretendía conseguir que el creciente número de comunicaciones que se presentaban a los congresos y que mostraban la vitalidad de la investigación que se estaba realizando se plasmase también en un buen número de artículos científicos que dejasen constancia de los resultados obtenidos. Al mismo tiempo se aspiraba a conseguir, mediante un proceso editorial riguroso y transparente, la inclusión en las bases de datos de fuentes primarias de mayor prestigio.

Desde enero de 2014 FARMACÉUTICOS COMUNITARIOS se publica exclusivamente en formato electrónico, aunque manteniendo la maquetación original de la revista impresa. El acceso es libre y gratuito sin necesidad de registro y se encuentran disponibles para consulta o descarga también todos los números anteriores. Es una revista revisada por pares; es decir, que todos los artículos son enviados para su revisión por al menos dos miembros del comité científico, expertos en el área temática tratada, que evalúan su calidad. Los autores desconocen la identidad de los revisores y estos la de aquellos. Los revisores forman parte del Área Científica de SEFAC y constituyen, con los autores, los pilares fundamentales de la revista. Son todos profesionales de prestigio, especialistas en los diversos campos de enfoque de la revista, pertenecientes a los más variados ámbitos: farmacéuticos comunitarios, de atención primaria y hospital, médicos, enfermeras, profesores universitarios, españoles y de otros países.

En el año 2018 llegamos al décimo volumen de esta nueva etapa y creemos que es buen momento para recapitular, analizar el recorrido efectuado y reflexionar sobre los nuevos retos que nos plantea el futuro.

En los nueve volúmenes, 35 números, que hasta ahora han visto la luz se publicaron 232 artículos, 25,8 artículos por año y 6,9 artículos por número. Tras la revisión editorial y científica se rechazaron 37 manuscritos, el 15,2\% de los presentados. La tipología más frecuente fue: originales, incluyendo originales breves (97), editoriales (41), artículos especiales (23) y casos clínicos (19). 9 fueron documentos de SEFAC de autoría colectiva, 5 documentos de Foro de Atención Farmacéutica y 4 documentos de consenso de varias sociedades científicas en las que se incluía SEFAC.

440 autores publicaron al menos 1 artículo, de los que 98 publicaron más de 1 , 


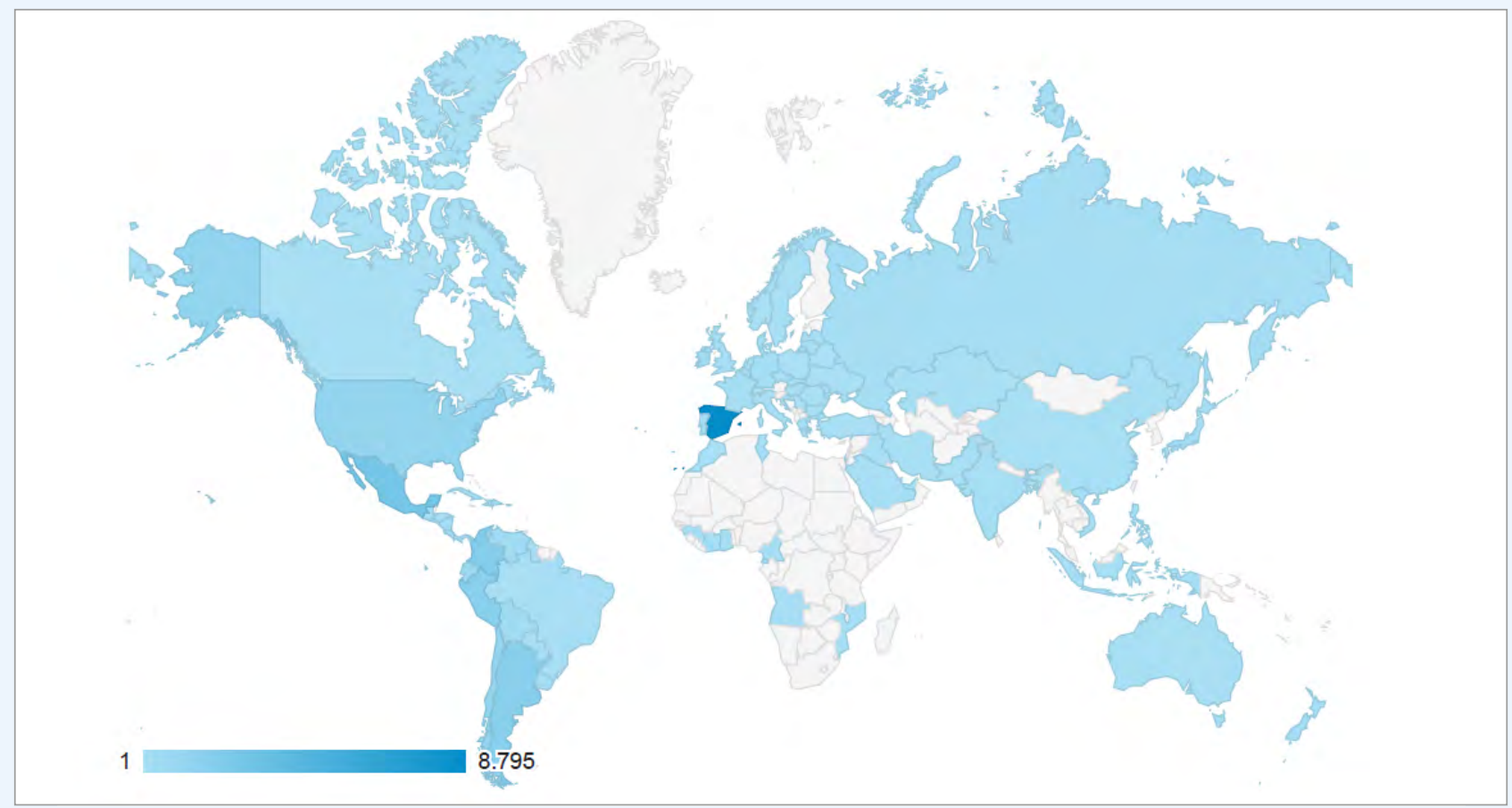

Procedencia de las visitas a la web de FARMACÉUTICOS COMUNITARIOS

y solo cuatro autores más de 10. Su procedencia geográfica incluye 14 comunidades y una ciudad autónoma, siendo las comunidades con mayor número de artículos Galicia (39), Madrid (33), Andalucía (32) y Comunidad Valenciana (31). También tenemos autores de Portugal, México, Costa Rica y Argentina. Las profesiones y ámbitos de ejercicio son muy variados. Lógicamente la mayoría son farmacéuticos comunitarios, pero también los hay de hospital, de atención primaria (AP), la industria, la distribución y de instituciones como los Colegios de Farmacéuticos (CIM) o del Departamento Técnico del Consejo General. Numerosas colaboraciones de médicos de AP y especialistas, formando equipos multidisciplinares con farmacéuticos, o participando con sus sociedades científicas en documentos de consenso, pero también alumnos de Medicina y Farmacia, enfermeras, veterinarios, biólogos, economistas, estadísticos, psicólogos y abogados.

Los datos de difusión de la revista a través de Internet son especialmente satisfactorios. En el cuarto trimestre de 2017 recibimos 33.363 visitas de 20.965 usuarios, con un incremento con respecto al mismo período de 2016 del 10,6\% en el número de visitas y del 17,4\% en el número de visitantes. El porcentaje de visitantes que repetían visita pasó del 87,2\% en el período indicado de 2016 al 88,3\% en el de 2017. La procedencia de las visitas es en su mayoría de fuera de España, con un incremento importante en este sentido en 2017 (62,3\%) frente a 2016 (54,4\%), siendo México, con un $11,5 \%$, el país con mayor número de visitas.

La labor de los revisores es fundamental para conseguir una revista de calidad. Tiene un doble objetivo: realiza un papel de filtro evaluando la validez científica, la trascendencia y la originalidad de la obra y, al mismo tiempo, permite a los revisores proponer mejoras en la redacción, estructura o planteamiento del trabajo expuesto. Al final del proceso el manuscrito inicial ha sufrido cambios que pulen su contenido hasta alcanzar el nivel requerido para su publicación. Los comentarios y sugerencias de los revisores, generalmente personas con amplia experiencia en el diseño y la publicación de trabajos científicos, es una excelente oportunidad de aprendizaje para autores noveles.

El tiempo medio de las revisiones, contabilizado desde que se recibe el manuscrito hasta el momento en que es aceptado, fue en 2017 de 58 días. No es un plazo excesivo en relación a otras revistas y va mejorando cada año (89 días en 2015 y 65 en 2016), pero creemos que debe todavía agilizarse.

Todos los que formamos parte de FARMACÉUTICOS COMUNITARIOS: autores, comité editorial, revisores, equipo de SEFAC y colaboradores editoriales podemos sentirnos razonablemente orgullosos de lo conseguido hasta ahora. Es una revista joven, de puntual periodicidad trimestral, que se está consolidado entre las publicaciones biomédicas del ámbito de la atención primaria en España, presente en las bases de datos de varias universidades, que alcanza una amplia difusión en prácticamente todo el mundo, con especial repercusión en Hispanoamérica y que cada año incrementa su incorporación a las bases de datos de la literatura científica.

Pero siguen existiendo asignaturas pendientes, que necesariamente tendremos que superar para alcanzar los máximos objetivos a los que SEFAC aspira. Creemos que el camino emprendido es el adecuado: la investigación en farmacia comunitaria tiene una enorme vitalidad, como lo demuestran los numerosos proyectos de investigación que nuestra sociedad, junto con otras sociedades científicas tiene en marcha, las tesis doctorales, trabajos de fin de grado, proyectos de fin de máster realizados por farmacéuticos comunitarios o las numerosas comunicaciones que se presentan a nuestros congresos. Buena parte de esa investigación se pierde, no llega a ser conocida por el resto de profesionales ni por la sociedad.

FARMACÉUTICOS COMUNITARIOS es un vehículo apropiado, diría que el ideal, para darle difusión. Por las rigurosas y transparentes características de su proceso editorial y el nivel de sus indexaciones, es aceptada hoy por algunas universidades como soporte válido para las publicaciones preceptivas en el proceso de la consecución del doctorado. Se contempla también en los baremos para concursos de la Administración en condiciones de igualdad con otras revistas del ámbito biomédico. Conseguiremos así el continuo incremento en el número y calidad de artículos publicados necesario para continuar avanzando paso a paso en el objetivo de lograr que la investigación en farmacia comunitaria consiga la inclusión en los más prestigiosos indexadores. 